\title{
Malposition of Septum Primum
}

\author{
Maryam Moradian
}

\section{Abstract}

Septum primum malposition is responsible for different degrees of abnormal drainage of pulmonary veins. It is usually accompanied by heterotaxy and polysplenia. Abnormal deviation of septum primum toward the anatomic left atrium in echocardiography should rise the suspicion of this diagnosis.

\section{Malposition of Septum Primum}

1. IF in four chamber view septum primum is displaced toward the anatomic left atrium (LA) and results in the drainage of some or all the pulmonary veins into the morphologic right atrium (RA) malposition of septum primum should be considered

2. Pay attention that pulmonary veins are normally connected to posterior wall of morphologic LA (Fig. 10.1)

3. Remember that septum primum may not reach the posterior wall of LA so there will be an intera atrial communication that is a "septum primum mal position defect "not ASD or PFO. Sometimes septum primum has multiple small fenestrations.

4. Don't forget that this anomaly is more common in heterotaxy, polysplenia, and hypoplastic left heart syndrome patients

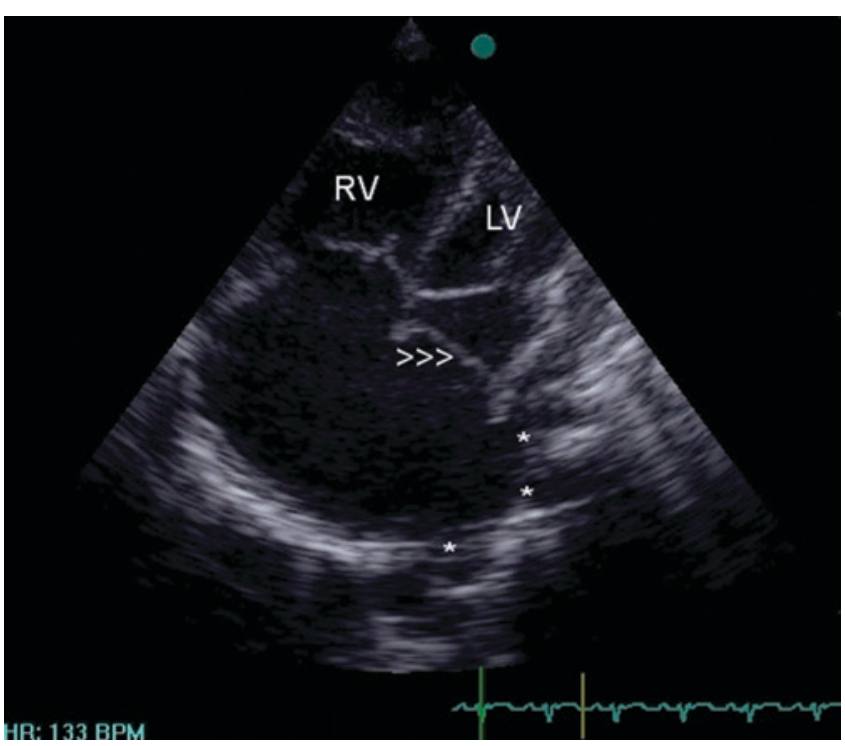

Fig. 10.1 Apical four chamber view showing leftward malposition of septum primum (arrow heads). Asterisks indicate normal connection of pulmonary veins to posterior wall of LA

\section{Suggested Reading}

Brown DW, Geva T. Anomalies of pulmonary veins (Chapter 35). In: Allen HD, Shaddy RE, Penny DJ, Feltes TF, Cetta F editors. Moss and Adams' heart disease in infants, children, and adolescents including the fetus and young adults. 9th ed. Wolters Kluwer 2016, pp. 881-910

Cuttone F, Hadeed K, Lacour-Gayet F, Lucron H, Hascoet S, Acar P, et al. Isolated severe leftward displacement of the septum primum: anatomic and 3D echocardiographic findings and surgical repair. Interact CardioVasc Thorac Surg. 2017;24:772-7.

Gajjar T, Desai N. Septum primum malposition defect: a rare congenital anomaly. Türk Gögüs Kalp Damar Cerrahi si Dergi si. 2013;21(1):245-9.

Park MV, et al. Leftward displacement of septum primum in hypoplastic left heart syndrome. Pediatr Cardiol. 2013;34(4):942-7.

\section{Moradian $(\square)$}

Pediatric Cardiology, Rajaie Cardiovascular, Medical \& Research

Center, Iran University of Medical Sciences, Tehran, Iran 